\title{
3 Research Square \\ Body Mass Index and Healthcare Costs: Using Genetic Variants from the HUNT Study as Instrumental Variables
}

Christina Hansen Edwards ( $\square$ christina.hansen.edwards@fhi.no )

Norwegian Institute of Public Health

Gunnhild Åberge Vie

Norwegian Institute of Public Health

Christina Hansen Edwards

Norwegian Institute of Public Health

\section{Research Article}

Keywords: Body mass index, Health care costs, Causation, Mendelian randomization, Instrumental variables, Obesity

Posted Date: July 26th, 2021

DOI: https://doi.org/10.21203/rs.3.rs-701491/v1

License: (9) This work is licensed under a Creative Commons Attribution 4.0 International License. Read Full License

Version of Record: A version of this preprint was published at BMC Health Services Research on March 25th, 2022. See the published version at https://doi.org/10.1186/s12913-022-07597-z. 


\section{Abstract}

Background: Past studies have found associations between obesity and healthcare costs, however, these studies have suffered from bias due to omitted variables, reverse causality, and omitted variables.

Methods: We used genetic variants related to body mass index (BMI) as instruments for BMl; thereby exploiting the natural randomization of genetic variants that occurs at conception. We used data on measured height and weight, genetic information, and sociodemographic factors from the NordTrøndelag Health Studies (HUNT), and individual-level registry data on healthcare costs, educational level, registration status, and biological relatives. We studied associations between $\mathrm{BMI}$ and general practitioner (GP)-, specialist-, and total healthcare costs in the Norwegian setting using instrumental variable (IV) regressions, and compared our findings with effect estimates from ordinary least squares (OLS) regressions. The sensitivity of our findings to underlying IV-assumptions was explored using twosample Mendelian randomization methods, non-linear analyses, sex-, healthcare provider-, and agespecific analyses, within-family analyses, and outlier removal. We also conducted power calculations to assess the likelihood of detecting an effect given our sample 60786 individuals.

Results: We found that increased BMI resulted in significantly higher GP costs; however, the IV-based effect estimate was smaller than the OLS-based estimate. We found no evidence of an association between $\mathrm{BMI}$ and specialist or total healthcare costs.

Conclusions: The effect of obesity on GP- and specialist costs may have been overestimated in previous studies.

\section{Introduction}

Obesity is highly prevalent in populations around the world [1], and a vast array of prevention strategies and treatments have been proposed to mitigate the epidemic [2-5]. Economic evaluations of potential strategies and treatments are needed to identify how resources should be invested. Correct identification of cost-effective interventions requires that accurate data on the costs of obesity are used in economic evaluations.

A multitude of studies have assessed the costs of obesity, and the findings of these studies have been summarized in several reviews [6-16] that conclude that the economic burden of obesity is substantial. Traditionally, studies have typically used cross-sectional or longitudinal data to assess the costs of obesity [14]. These study designs have some shortcomings that can lead to bias when estimating the effect of body mass index (BMI) on healthcare costs. One of the main challenges is that several obesityassociated diseases are both risk factors for obesity and complications of obesity, and that healthcare use in itself can result in increased BMI (for example due to side effects of medications [17]). Studies using cross-sectional data cannot overcome this issue because adjusting for obesity-related diseases could lead to over-adjustment. Data from longitudinal studies can be used to net out all time constant 
characteristics. However, bias from variables that change over time will still be present, which means that simultaneity bias can be reduced, but not eliminated by using longitudinal data.

Another limitation is that most past studies use self-reported BMI or healthcare costs in their calculations. S Kent, F Fusco, A Gray, SA Jebb, BJ Cairns and B Mihaylova [14] found that 55 of the 75 studies included in their review used self-reported weight and/or height to estimate BMI. Measurement error in BMI due to self-reporting bias typically leads to an underestimation of true BMI [18, 19]. Moreover 16 of the 75 studies used self-reported data on healthcare costs [14]. Often, individuals are unable to correctly recall the number of past healthcare contacts made, especially if contact frequency is high [20]. In standard linear regressions, measurement error in the independent variable may bias regression estimates towards zero, and measurement error in the dependent variable may increase variance hence decreasing power to detect a causal effect.

One way to overcome at least some of these endogenetiy issues is by using an instrumental variable (IV) approach. In IV-analyses, omitted variable bias can be avoided if the instrument is uncorrelated with the omitted variables. In the context of obesity, simultaneity bias can also be largely avoided if the instrument used is constant throughout life. Measurement error can lead to bias even though an IV-approach is used [21], and therefore measured height and weight, combined with registry data on healthcare utilization can increase reliability of estimates from IV models.

In recent studies, the natural randomization that occurs due to the random allocation of genetic variants at conception has been exploited by using genetic information as instrumental variables. The first studies to make use of genetic information in IV-analyses used the height and/or weight of biological relative(s) as instruments [22-26]. These studies found that elevated BMI was associated with higher healthcare costs than when using non-IV methods. A potential limitation of using anthropometric measures of relatives is that effects of the household environment on the association between $\mathrm{BMI}$ and healthcare costs cannot be ruled out.

In two more recent studies, P Dixon, W Hollingworth, S Harrison, NM Davies and GD Smith [27], and CF Kurz and M Laxy [28] have tried to minimize bias from environmental concerns by conducting Mendelian randomization (MR) analyses, that is, by using genetic variants associated with $\mathrm{BMI}$ as instruments. The first study used a UK Biobank sample, and found that obesity was associated with higher hospital costs than when using non-IV models [27]. The second study, using data from South-Western Germany, found that obesity resulted in total healthcare costs that were over twice as large compared with non-IV based estimates [28]. Both of these studies have important limitations. The sample used by CF Kurz and M Laxy [28] is small for the MR context $(n=2796)$, and the majority $(99.5 \%)$ of the individuals included in the sample used by P Dixon, W Hollingworth, S Harrison, NM Davies and GD Smith [27] were between 40 and 69 years of age. In addition, as P Dixon, W Hollingworth, S Harrison, NM Davies and GD Smith [27] point out, their sample population has lower mortality, lower levels of morbidity increasing behaviors, and are better educated than the wider UK population. Moreover, neither of these studies investigated the effect of $\mathrm{BMI}$ on general practitioner (GP) costs. Studying the effects of GP costs gives an increased 
understanding of the consequences of obesity, because the mechanisms driving GP costs may differ from those of specialist costs.

Our study uses a sample with an appropriate size for the MR context, includes adults aged 20 years and above, and can be considered largely representative of the Norwegian population. We have combined genotyped data from biological samples with data on measured height and weight, registry-based healthcare costs, sociodemographic variables, and relatedness. The objective of the study was to use genetic variants associated with BMI as instruments to estimate the effect of BMI on GP-, specialist-, and total costs in Norway. This was achieved by: 1) Estimating association setween BMI and GP-, specialist-, and total costs using ordinary-least squares (OLS) regression. 2) Re-estimating the same associations using two-stage least squares (2SLS) with three different genetic instruments that were generated based on 97 BMl-associated genetic variants [29]. 3) Conducting sensitivity analyses, including two-sample methods (inverse-variance weighted, MR-Egger, median-weighted, and modal weighted estimation), nonlinear methods, sex-, healthcare provider, and age-specific analyses, within-family analyses using familyfixed effects, and outlier removal; to explore the robustness of our estimates and the validity of our instruments. We then discussed the findings from stages $1-3$, and inferred about the causal effect of obesity on healthcare costs.

\section{Methods}

\subsection{Data}

In this study, we used a combination of survey data and registry-based data. The five primary data sources used are presented in Figure 1.

\section{Data on BMI, sociodemographic factors, and genetic information}

The HUNT study has been described in detail elsewhere [30, 31]. In brief, the HUNT study is a populationbased cohort study. All inhabitants of Nord-Trøndelag (a rural geographical region in Central Norway) who turned 20 years of age during the study period were invited to participate. So far, four waves have been conducted, and we have used data from the second (HUNT 2) and third (HUNT 3) waves. The first wave did not contain genetic information, and the results from the fourth wave were unavailable at study initiation. Of those that were invited to take part in the study, $69.5 \%(n=65261)$ of adults in HUNT 2, and $54.1 \%(n=50$ 809) of the adults in HUNT 3 participated. Data were collected between August 1995 and June 1997 (HUNT 2), and between October 2006 and June 2008 (HUNT 3). The studies consisted of questionnaires, clinical measurements, and collection of biological materials for DNA genotyping (performed using Illumina HumanCoreExome arrays). We used information about participants' measured height and weight, socioeconomic variables (including age, sex, marital status, urbanity, and smoking status), genetic variants related to obesity, and genetic principal components. If the same individuals had 
participated in both HUNT 2 and HUNT 3, we used data from HUNT 3 (Figure 1) since this was closer to the time at which healthcare costs were measured.

\section{Data on healthcare costs}

The Norwegian healthcare system is divided into primary- and specialist care. All registered inhabitants have a right to a regular GP, and approximately $99 \%$ of inhabitants are registered within the GP system [32]. GP services are part of the primary care sector, and GPs have a gatekeeping function so patients need a referral from primary care to access specialist care. Norway has a universal and publicly financed healthcare system, which is free for all children up to age 16 (18 for mental health services). For adults outpatient health services are subsidized and inpatient care is free. Nearly all specialist care and GP costs are included in the Norwegian Patient Register (NPR) and The Norwegian Control and Distribution of Health Reimbursement Database (KUHR). The NPR also contains information about utilization of private institutions and specialists that are contracted to the public healthcare system [33]. Some healthcare costs are not included in our data, and these include for example: physiotherapy, nursing home costs, and dental care.

We used a de-identified key to link the data from HUNT with data from the NPR and the KUHR database. Norwegian hospitals are partly reimbursed via activity-based financing, and these reimbursements are based on the Diagnosis Related Group (DRG)-system. Our specialist care data included data on somatic, psychiatric, and substance abuse-related inpatient and outpatient contacts that occurred from 2009 to 2016. For episodes of care for which DRG-weights were available, we multiplied the DRG-weight pertaining to each particular episode by the average price of a DRG [34-41] (i.e. average patient cost) for the year during which the DRG was registered. Where DRG-weights were not available (such as for psychiatric contacts) we used data on the average cost of similar contacts for that particular year (details are available in the Additional information). We then summed the costs for each year per patient for the years that the patient was alive and living in Norway, and adjusted the yearly costs to 2016 price levels $[42,43]$. Finally, we calculated the average yearly specialist cost per patient during the study period.

The KUHR database contains all electronic patient claims made by general practitioners, and includes information about reimbursed amounts, and patient co-payments for all consultations. To compute GP costs we summed reimbursed amounts and co-payments for each patient for each year between 2009 and 2016 that the patient was alive and living in Norway. We then adjusted the costs to 2016 price levels, and calculated the average yearly cost per patient. All costs were converted from Norwegian Kroner (NOK) to 2016 Euros $(1.00 €=$ NOK 9.29) [44].

\section{Data on education, registration status, and relatedness}

Next, we linked our dataset with data on educational level from the NUDB database. Age, sex, marital status, urbanity, smoking status, and BMI was measured during the HUNT studies, and were therefore 
registered at approximately the same time as BMI was measured. For consistency we therefore used education in 1996 for those with a BMI registered in HUNT 2 and educational level registered in 2007 for those whose BMI was reported in HUNT3. The dataset was then linked with data from the Norwegian Population Register on registration status, and individuals were included only during the years that they were alive and living in Norway. Finally, our data were combined with data on relatedness, which allowed us to identify individuals with the same parents.

\subsection{Regression models}

We investigated the effect of BMI on average yearly GP cost, specialist costs, and total costs using a naïve OLS model, and using a 2SLS IV-regression using genetic variants as instruments. In the first-stage of the 2SLS model, we regressed BMI on the genetic instrument, and in the second-stage, we used the predicted values from the first-stage to estimate the association between BMI and healthcare costs and adjusted the standard errors accordingly.

Since genetic variants are randomly allocated at conception conditional on parental genes, genetic instruments should not be confounded by other variables. However, the relationship between genetic factors and phenotype expression is not fully understood [45], and if adjusting for potential confounders alters the findings then this could indicate that there is a problem with the instrument, and could warrant further investigation. Also, adjusting for confounders might reduce the residual variability of the dependent variable. We explored adjusting for: i) study period (HUNT 2 or HUNT 3), data years (years of data each participant was residing in Norway) (categorical: 1 - 8 years), birth year (categorical: years 1906 - 1989), and sex (categorical), and ii) study period, data years, birth year, sex, educational level (categorical), marital status (categorical), smoking status (categorical), and urbanity (categorical). In the MR analyses, we also explored the effect of adjusting for the first 10 principal components, to adjust for potential population stratification. The statistical power to detect an effect of BMI on GP-, and specialistcost given our sample of 60786 individuals was estimated using the mRnd power calculator [46]. Details of the power analyses are available in the additional information and the results are depicted in Figure S1.

\subsection{The genetic instruments}

AE Locke, B Kahali, SI Berndt, AE Justice, TH Pers, FR Day, C Powell, S Vedantam, ML Buchkovich and J Yang [29] present 97 genetic variants that have been found to be associated with BMI in genome wide association studies (GWAS), and report the strength of the association between each of these variants and BMI. Only one of these variants (rs12016871) were unavailable in our dataset, and for this variant we followed M Brandkvist, JH Bjørngaard, RA Ødegård, BO Åsvold, ER Sund and GÅ Vie [47], and used variant rs4771122 as a proxy. IV-analyses were conducted with three instruments: Instrument 1: An unweighted genetic risk score (GRS) based on the sum of the number of BMI-increasing alleles, out of the $97 \mathrm{BMI}-$ increasing alleles, for each participant. Instrument 2: A weighted GRS which was computed by 
multiplying the number of BMI-increasing alleles by the respective beta-coefficients from the study by $A E$ Locke, B Kahali, SI Berndt, AE Justice, TH Pers, FR Day, C Powell, S Vedantam, ML Buchkovich and J Yang [29], and then summing the product for each participant. For the sex-stratified analyses we developed sexspecific weighted GRSs using the sex-specific beta-coefficients reported by AE Locke, B Kahali, SI Berndt, AE Justice, TH Pers, FR Day, C Powell, S Vedantam, ML Buchkovich and J Yang [29]. Instrument 3: Including the two genetic variants with the strongest association with BMI (FTO (rs1558902) and MC4R (rs6567160) as dummy variables.

\subsection{Instrument validity}

Three conditions must be satisfied for an instrument to be regarded as valid.

1) The instrument must be highly correlated with the variables being instrumented, conditional on the other variables in the model (the relevance assumption). In the GWAS that we used to select genetic variants for our instrument, each of the genetic variants were found to be associated with BMI [29], and this has been confirmed in a more recent GWAS [48]. However, the strength of the correlation between each genetic variant and BMI varied between the genetic variants. An instrument can be considered weak if the first-stage F-statistic in the IV-regressions is smaller than $10(F<10)$ [49]. A weak instrument will bias the 2SLS estimates towards the OLS estimate [50]. Combining genetic variants into a GRS, as we have done in this study, leads to a higher first-stage F-statistic, and reduced bias [51].

2) There should not be any omitted variables (measured or unmeasured) on the pathway between the instrument and BMI (the independence assumption). The allocation of genes at conception can be regarded as random, and therefore we assume that the independence assumption largely holds. However, there are some potential problems, for example: i) mating can be non-random since individuals with similar phenotypes are more likely to mate (assortative mating), ii) genes are conditional on parents genes (dynastic effects), iii) one or more non-confounding variables can modify the effect of the genetic variants on healthcare costs (effect modification), iv) some allele variants are more likely to be inherited together than one would expect from chance (linkage disequilibrium) and if these overrepresented alleles lead to increased healthcare costs through pathways that are unrelated to BMI, then the study is likely to be biased [51]. And v) there are differences in the allele-frequencies of particular population sub-groups due to differential ancestry (population stratification) [52]. The independence assumption is not fully testable, but some methods, that will be described later, have been developed to assess some of the factors that can lead to violations of the independence assumption.

3) Each genetic variant should only affect healthcare costs via BMI (the exclusion restriction). This condition cannot be verified and will be violated if genetic variants that have been shown to be associated with BMI are simultaneously associated with other phenotypic traits that are unrelated to BMI (horizontal pleiotropic effects), but related to healthcare costs. Since the biological understanding of each of the genetic variants used in our study is limited, the extent of horizontal pleiotropy is unknown. Other possible violations of the exclusion restriction include, but are not limited to: linkage disequilibrium, 
population stratification, and effect modification. In the next section, we will describe analyses that we have done to investigate the potential violations of the IV-assumptions.

\subsection{Sensitivity analyses}

To investigate the possibility of bias in our estimates we conducted a series of sensitivity analyses, including two-sample methods, non-linear analyses, sex-, healthcare provider-, and age-specific analyses, within-family analyses, and outlier removal.

\subsubsection{Two sample methods}

The two-sample MR methods involved combining summary data on the genetic variant-BMI association from AE Locke, B Kahali, SI Berndt, AE Justice, TH Pers, FR Day, C Powell, S Vedantam, ML Buchkovich and $J$ Yang [29] with data on the association between the genetic variants and GP-, specialist-, and totalcosts, estimated from our data. The overlap between our sample and the data used by AE Locke, $B$ Kahali, SI Berndt, AE Justice, TH Pers, FR Day, C Powell, S Vedantam, ML Buchkovich and J Yang [29] was minimal, and both studies provide results from samples with similar ancestries (European descent), and adjust for age and sex [29]. When the samples used in two-sample analyses are independent, the twosample estimates will be biased towards zero, rather than the observational estimate [53].

We began by testing for heterogeneity of the genetic instruments using Cochran's $Q$ test. If there is more heterogeneity than one would expect from chance, then this might indicate violation of the IVassumptions, for instance due to horizontal pleiotropy [54].

We further evaluate heterogeneity by applying the following two-sample methods: Inverse variance weighted estimation (IVW), MR-Egger regression (including MR-Egger with a SIMEX (Simulation Extrapolation) correction, weighted median estimation, and weighted mode-based estimation). These methods primarily examine violations of the exclusion restriction, particularly horizontal pleiotropy. The methods rely on different assumptions that can only be partially tested. Thus, comparing findings from the different methods is advantageous as this can reveal various potential threats to the IV-assumptions.

The Inverse variance weighted (IVW) method is a weighted linear regression of the summary SNPhealthcare cost association on the summary SNP-BMI associations, with the intercept constrained to zero $[55,56]$. The IVW estimate is similar to the 2SLS estimate, and will be a poor estimate if there is bias due to pleiotropy. The IVW method also requires the InSIDE assumption (Instrument strength independent of direct effects), that any pleiotropic effects on the outcome are independent of the SNP-BMI associations, and the NOME assumption, that there is no measurement error in the SNPs exposure association, to hold.

The MR-Egger method is similar to the IVW method, but the intercept is not constrained to pass through zero [54]. As with the IVW method, MR-Egger also requires that the InSIDE and NOME assumptions hold [55]. Bias due to measurement error was estimated using the regression dilution statistic ( ). If was 
$<90 \%$, we used the SIMEX (Simulation Extrapolation) correction [55]. When this correction is applied the SNP-BMI associations are estimated in repeated simulations before they are combined with the SNPhealthcare cost associations [55]. It is not possible to test the InSIDE assumption, but if it holds the slope estimated from MR-Egger regression can be interpreted as the true estimate under pleiotropy [54], and the intercept can be interpreted as an estimate of the average pleiotropic effect across the instruments [55]. The MR-Egger estimates are less precise and have low power [57].

The weighted median approach uses the median of the inverse-variance weighted ratio estimates $[57,58]$. This method is more robust to outliers than IVW and MR-Egger, and provides a consistent estimate if at least $50 \%$ of the weight comes from genetic variants that are valid instruments [57].

The weighted mode approach uses the mode of the inverse-variance weighted ratio estimates [58]. This approach is more powerful than the MR-Egger and less powerful than the IVW and weighted-median approaches, and will give a consistent estimate if the largest weights originate from valid genetic variants [59]. This method requires that the zero modal pleiotropy assumption (ZEMPA) (i.e. that the most common effect is a consistent estimate of the true causal effect) holds [59]. This assumption was assessed by constructing density plots and inspecting these fore multiple peaks [59].

To ease interpretation of our findings, we followed A Budu-Aggrey, B Brumpton, J Tyrrell, S Watkins, EH Modalsli, C Celis-Morales, LD Ferguson, GÅ Vie, T Palmer and LG Fritsche [60], and P Dixon, W Hollingworth, S Harrison, NM Davies and GD Smith [27], and transformed the two-sample estimates to natural BMI-units by dividing the estimates by the median standard deviation (4.6) of BMI reported by $\mathrm{AE}$ Locke, B Kahali, SI Berndt, AE Justice, TH Pers, FR Day, C Powell, S Vedantam, ML Buchkovich and J Yang [29]. As a result, the estimates from the two-sample methods can be interpreted as the marginal effect of a one-unit increase in BMI on healthcare costs.

\subsubsection{Non-linear analyses}

The associations between BMI and healthcare outcomes may be nonlinear [25, 61, 62]. Genetic variants explain a relatively small proportion of variance in BMI, and therefore non-linear effects might be challenging to detect. We used a method proposed by JR Staley and S Burgess [63] to assess nonlinearity in studies using genetic variants as instruments. The method includes two tests for nonlinearity: a quadratic and a fractional polynomial test. The sample was divided into 10 strata using residual BMI, and then linear IV-regression estimates were calculated for each stratum by dividing the association between the GRS and each healthcare cost outcome by the association between the GRS and BMI. Next, a meta-regression was performed, where the estimated values for each stratum are regressed against the mean of $\mathrm{BMI}$ in each stratum using a flexible semiparametric framework.

\subsubsection{Stratified analyses}

We performed analyses stratified by sex, and specialist healthcare provider (somatic hospital care, psychiatric hospital care, providers of somatic and psychiatric care that were contracted to specialist 
care, and contacts related to interdisciplinary specialized drug treatment).

\subsubsection{Within family analyses}

These analyses can provide information about the effect of possible violations of the IV-assumptions due to assortative mating, dynastic effects and population stratification [64]. There are several proposed methodological variations of within-family analyses [64]. We conducted a 2SLS regression with familyfixed effects. These analyses require more power than population-based methods.

\subsubsection{Outlier removal}

We identified outlying genetic variants from forest plots of the effect of each of the genetic variants on GP- and specialist costs. Next, we used the the PhenoScanner database [65], to check if these genetic variants had been found to be associated with non-BMI related phenotypes. Then we explored the effect of removing the outermost outliers from the analysis. If removal of an outlier substantially alters the estimators, and the removed variant is an invalid instrument, then including this variant in our instrument may have biased the results.

\subsection{Ethical approval}

The study was approved by the Regional Committee for Ethics in medical research (2016/537/REK midt).

\subsection{Software}

STATA 15 was used for the regression analyses and $\mathrm{R}$ version 3.4.1 for data processing. The MR robust package [66] was used for two-sample MR analyses.

\section{Results}

Our dataset contained information about $\mathrm{BMI}$, genetic variants related to $\mathrm{BMI}$, sociodemographic variables (Table 1), GP-, specialist- and total costs (Table 1) for 60786 individuals.

Table 1: Descriptive information by sex. 


\begin{tabular}{|c|c|c|c|}
\hline \multirow[t]{3}{*}{ Variable } & \multirow[t]{3}{*}{ Category } & \multicolumn{2}{|l|}{ Sex } \\
\hline & & Male & Female \\
\hline & & $\mathrm{N}(\%)$ & $\mathrm{N}(\%)$ \\
\hline Total & & $28136(100)$ & $32650(100)$ \\
\hline \multirow[t]{6}{*}{ Age } & $18-24$ & $1843(6.6)$ & $2247(6.9)$ \\
\hline & $25-44$ & $8587(30.5)$ & 9919 (30.4) \\
\hline & $45-66$ & $12553(44.6)$ & $13836(42.4)$ \\
\hline & $67-79$ & $4256(15.1)$ & $5298(16.2)$ \\
\hline & $80+$ & $897(3.2)$ & $1350(4.1 \%)$ \\
\hline & Missing & $0(0.0)$ & $0(0.0)$ \\
\hline \multirow[t]{5}{*}{ Marital Status } & Married/ Registered partner & $16432(58.4)$ & $17793(54.5)$ \\
\hline & Unmarried & $8321(29.6)$ & $7617(23.3)$ \\
\hline & Divorced/separated & $2475(8.8)$ & $3311(10.1)$ \\
\hline & Widow/Widower & $866(3.1)$ & $3883(11.9)$ \\
\hline & Missing & $42(0.2)$ & $46(0.1)$ \\
\hline \multirow[t]{5}{*}{ Education } & Primary school & $5978(21.3)$ & $8384(25.8)$ \\
\hline & Secondary school & $16027(57.1)$ & $15087(46.3)$ \\
\hline & Higher Education, short & $4420(15.7)$ & $8164(25.1)$ \\
\hline & Higher Education, long & 1651 (5.9) & $920(2.8)$ \\
\hline & Missing & $0(0.0)$ & $0(0.0)$ \\
\hline \multirow[t]{3}{*}{ Urbanity } & Urban & $18197(64.7)$ & $21165(64.8)$ \\
\hline & Rural & $9825(34.9)$ & 11299 (34.6) \\
\hline & Missing & $114(0.4)$ & $186(0.6)$ \\
\hline \multirow[t]{4}{*}{ Smoking status } & Smoker & $5589(19.9)$ & $7552(23.1)$ \\
\hline & Former smoker & 9474 (33.7) & $8873(27.2)$ \\
\hline & Never smoker & 11030 (39.2) & $14154(43.4)$ \\
\hline & Missing & $302(1.1)$ & $394(1.2)$ \\
\hline \multirow[t]{2}{*}{ BMI category ${ }^{a}$} & Underweight & $82(0.3)$ & $291(0.9)$ \\
\hline & Normal weight & 7777 (27.6) & 12674 (38.8) \\
\hline
\end{tabular}




\begin{tabular}{lll} 
Overweight & $14431(51.3)$ & $12181(37.3)$ \\
\hline Class I Obesity & $4869(17.3)$ & $5374(16.5)$ \\
\hline Class II Obesity & $977(3.5)$ & $2130(6.5)$ \\
\hline Missing & $0(0.0)$ & $0(0.0)$
\end{tabular}

a. The BMI-categories were defined as follows: Underweight $=$ BMl<18.5, normal weight $=$ BMI: 18.5-24.9, overweight $=$ BMI: $25.0-29.9$, class I obesity $=$ BMI: 30.0-34.9, and class II obesity $=$ BMI $\geq 35.0$.

The mean age of participants at BMI measurement was 51.1 years $(S . D=16.3)$ for males and 51.4 years (S.D=16.9) for females. The average BMI of the participants was $27.2 \mathrm{~kg} / \mathrm{m}^{2}(\mathrm{~S} . \mathrm{D}=3.8)$ for males, and $26.9 \mathrm{~kg} / \mathrm{m}^{2}(\mathrm{~S} . \mathrm{D}=4.9)$ for females. During the eight-year study period, $98.7 \%(\mathrm{n}=27775)$ of males, and 99.2\% ( $n=32397)$ of females had incurred costs for GP services, and $68.2 \%(n=19180)$ of males, and $69.2 \%$ ( $n=22588$ ) of females had incurred costs for specialist services. The average crude GP- and specialist costs generally increased with BMI, but costs were also high for males and females with underweight (Table 3 ). The average yearly GP cost was $€ 161.8(S . D=177.7$, median $=108.1)$ for males, and $€ 196.5$ (S.D $=182.7$, median=149.8) for females. The average yearly specialist cost was, $€ 2233.9$ $(S . D=6698.0$, median = 226.4) for males, and $€ 2066.1$ (S.D = 5 702.0, median= 370.9) for females.

Table 2: Mean (standard deviation (S.D)) crude sex-and BMI-specific yearly healthcare costs 


\begin{tabular}{|c|c|c|c|}
\hline & & \multicolumn{2}{|l|}{ Sex } \\
\hline & & Male & Female \\
\hline Type of healthcare & BMI-category ${ }^{a}$ & Mean (S.D) $(€)$ & Mean (S.D) $(€)$ \\
\hline \multirow{5}{*}{ GP costs } & Underweight & $122.2(121.2)$ & 224.1 (232.1) \\
\hline & Normal weight & $134.7(165.8)$ & $166.4(161.5)$ \\
\hline & Overweight & $157.3(166.8)$ & 196.6 (177.9) \\
\hline & Class I Obesity & 198.1 (195.3) & 232.4 (201.5) \\
\hline & Class II Obesity & $267.9(253.9)$ & $280.4(223.2)$ \\
\hline \multirow{5}{*}{$\begin{array}{l}\text { Specialist } \\
\text { Costs }\end{array}$} & Underweight & 2496.0 (6 469.4) & 3724.2 (11 101.2) \\
\hline & Normal weight & 1949.7 (5 982.9) & 1716.1 (5 376.6) \\
\hline & Overweight & 2225.4 (7 046.7) & 2019.0 (4 996.4) \\
\hline & Class I Obesity & 2387.8 (5 839.9) & 2566.2 (7 108.5) \\
\hline & Class II Obesity & 3831.7 (9 849.7) & 2930.8 (6 073.2) \\
\hline \multirow[t]{5}{*}{ Total costs } & Underweight & 2618.3 (6 517.7) & 3948.4 (11 179.3) \\
\hline & Normal weight & $2084.4(6040.3)$ & 1882.5 (5 425.1) \\
\hline & Overweight & 2382.7 (7 096.4) & 2215.5 (5 058.6) \\
\hline & Class I Obesity & 2585.9 (5 915.0) & 2798.6 (7 167.9) \\
\hline & Class II Obesity & 4099.6 (9 934.7) & 3211.2 (6 149.5) \\
\hline
\end{tabular}

a. The BMI-categories were defined as follows: Underweight $=$ BMl<18.5, normal weight $=$ BMI: 18.5-24.9, overweight $=$ BMI: $25.0-29.9$, class I obesity $=$ BMI: $30.0-34.9$, and class II obesity $=$ BMI $\geq 35.0$.

\subsection{Naïve OLS regression}

Increased BMI was significantly associated with higher costs for males and females, and with and without adjusting for potential confounding variables (Table 3).

Table 3: OLS estimates of the effect of BMI on GP-, specialist- and total costs. 


\begin{tabular}{lllll} 
Type of healthcare costs & Adjustment & Males \& females & Males & Females \\
\cline { 2 - 5 } & & Beta $(\mathrm{SE})(€)$ & Beta $(\mathrm{SE})(€)$ & Beta $(\mathrm{SE})(€)$ \\
\hline General practitioner costs & $\mathrm{I}^{\mathrm{a}}$ & $5.8(0.16)^{\star \star \star}$ & $7.0(0.26)^{\star \star \star}$ & $5.5(0.20)^{\star \star \star}$ \\
\cline { 2 - 5 } & II $^{\mathrm{b}}$ & $5.8(0.16)^{\star \star \star}$ & $6.9(0.26)^{\star \star \star}$ & $5.5(0.20)^{\star \star \star}$ \\
\hline Specialist costs & I & $44.6(5.40)^{\star \star \star}$ & $50.8(9.91)^{\star \star \star}$ & $45.2(6.24)^{\star \star \star}$ \\
\hline II & $52.0(5.48)^{\star \star \star}$ & $57.9(10.04)^{\star \star \star}$ & $50.8(6.34)^{\star \star \star}$ \\
\hline Total costs & I & $45.7(5.40)^{\star \star \star}$ & $52.1(9.91)^{\star \star \star}$ & $46.2(6.24)^{\star \star \star}$ \\
\hline & II & $53.0(5.48)^{\star \star \star}$ & $59.1(10.05)^{\star \star \star}$ & $51.8(6.34)^{\star \star \star}$
\end{tabular}

$\star \star \star \quad(p-v a l u e<0.001)$

a. Estimates were adjusted for study period, years of data available, birth year, and sex.

b. Estimates were adjusted for study period, years of data, birth year, sex, educational level, smoking status, marital status, and urbanity.

\subsection{SLS IV regressions}

The F-statistic was high, and well above 10 , for the three instruments in all the analyses, indicating that our instruments were strong (Table 4). We found a positive association between BMI and GP costs when using the unweighted ( $p$-value $<0.001$ ) and weighted GRSs ( $p$-value $<0.001$ ), and found no evidence of an association ( $p$-value $=0.398$ ) when using the FTO/MC4R instrument. The finding was consistent when potential covariates were added to the model (Additional information, Table S1), and when the first 10 principal components were added (Additional information, Table S2).

Compared with the OLS estimates (Table 3) adjusted for study period, years of data, sex, and birth year, the 2 SLS effect estimates were $14 \%$ larger when using the unweighted GRS, $3 \%$ smaller when using the weighted GRS, and $69 \%$ smaller when using the FTO and MC4R instrument.

Table 4: 2SLS estimates ${ }^{a}$ of the effect of BMI on GP-, specialist-, and total costs. 


\begin{tabular}{|c|c|c|c|c|}
\hline \multirow[t]{2}{*}{$\begin{array}{l}\text { Type of } \\
\text { healthcare cost }\end{array}$} & \multirow[t]{2}{*}{ Instrument } & \multirow[t]{2}{*}{$\begin{array}{l}\text { 2SLS First-stage Beta } \\
\text { instrument (SE) }\end{array}$} & \multirow[t]{2}{*}{$\begin{array}{l}\text { 2SLS Second-stage Beta } \\
\text { BMI (SE) € }\end{array}$} & \multirow[b]{2}{*}{ F-stat. } \\
\hline & & & & \\
\hline \multirow[t]{4}{*}{$\begin{array}{l}\text { General } \\
\text { practitioner costs }\end{array}$} & $\begin{array}{l}\text { Unweighted } \\
\text { GRS }\end{array}$ & $0.1(0.003)^{\star \star \star}$ & $6.6(1.177)^{\star \star \star}$ & 1123.0 \\
\hline & $\begin{array}{l}\text { Weighted } \\
\text { GRS }\end{array}$ & $4.0(0.105)^{\star \star \star}$ & $5.6(1.026)^{\star \star \star}$ & 1484.4 \\
\hline & FTO \& & $0.4(0.025)^{\star \star \star} \&$ & $1.8(2.116)$ & 173.2 \\
\hline & MC4R & $0.3(0.028)^{\star \star \star}$ & & \\
\hline \multirow[t]{4}{*}{ Specialist costs } & $\begin{array}{l}\text { Unweighted } \\
\text { GRS }\end{array}$ & $0.1(0.003)^{\star \star \star}$ & $2.3(40.035)$ & 1123.0 \\
\hline & $\begin{array}{l}\text { Weighted } \\
\text { GRS }\end{array}$ & $4.0(0.105)^{\star \star \star}$ & 14.9 (34.915) & 1484.4 \\
\hline & FTO \& & $0.4(0.025)^{\star \star \star} \&$ & $-0.3(71.640)$ & 173.2 \\
\hline & MC4R & $0.3(0.028)^{\star \star \star}$ & & \\
\hline \multirow[t]{4}{*}{ Total costs } & $\begin{array}{l}\text { Unweighted } \\
\text { GRS }\end{array}$ & $0.1(0.003)^{\star \star \star}$ & $3.3(40.053)$ & 1123.0 \\
\hline & $\begin{array}{l}\text { Weighted } \\
\text { GRS }\end{array}$ & $4.0(0.105)^{\star \star \star}$ & 15.8 (34.932) & 1484.4 \\
\hline & FTO \& & $0.4(0.025)^{\star \star \star} \&$ & $-0.4(71.675)$ & 173.2 \\
\hline & MC4R & $0.3(0.028)^{\star \star \star}$ & & \\
\hline
\end{tabular}

$\star \star \star *$-value $<0.001)$

a. The estimates were adjusted for study period (HUNT 2 or HUNT 3), years of data participants were alive and living in the country during the cost estimation period (2009-2016), sex, and birth year.

We did not find evidence of an association between $\mathrm{BMI}$ and specialist costs or between $\mathrm{BMI}$ and total costs, when using any of the three combinations of genetic variants as instruments. However, this could be due to a lack of power. The 2SLS coefficients (Table 4) were smaller, and had larger standard errors, compared with the OLS coefficients (Table 3 ). The same was found when adjusting for more potential covariates (Additional information, Table S1) and when adjusting for the first 10 principal components (Additional information, Table S2).

\subsection{Sensitivity Analyses}

\subsubsection{Two-sample Mendelian randomization}


The Cochran's $Q$ tests indicated that there was heterogeneity when assessing the association between $\mathrm{BMI}$ and GP costs $(\mathrm{Q}=131.5, \mathrm{p}$-value $=0.008)$, specialist costs $(\mathrm{Q}=129.1, \mathrm{p}$-value $=0.012)$, and total costs $(Q=128.5, p$-value $=0.013)$. Heterogeneity might suggest violations of the IV assumptions, for instance through horizontal pleiotropy.

The results of the two-sample methods are presented and together with the OLS and one-sample estimates. The regression dilution statistic () was 89.8, indicating that the MR-Egger estimate had a $10.2 \%$ relative bias towards the null. Since the bias was greater than $10 \%$, we also conducted an MREgger with SIMEX to adjust for attenuation bias.

For GP costs, there seemed to be some bias due to horizontal pleiotropy. The MR-Egger, median- and mode- based estimates also suggested that the true (pleiotropy-adjusted) estimate was below the IVW estimate (Figure 2, Additional information, Figure S3A). Evidence of horizontal pleiotropy was also found when plotting the effect-sizes for each genetic variant against the strength of the association between each genetic variant and BMI in a funnel plot (Additional information, Figure S2A).

We had no way of ascertaining whether the assumptions required for the MR-Egger estimate to hold were violated, and we have no reason to believe that the median-based estimate was unreliable. The modalbased estimate, however, should be interpreted with some caution, as we found some indication of modal pleiotropy (Additional information, Figure S6A). The p-values for all the two-sample estimates, except the IVW estimate, were weakly or not significant (Figure 2), but this could be due to a lack of power since these methods require more power to detect an effect than the one-sample methods.

For specialist costs, there were also some indications of horizontal pleiotropy (Figure 2, Additional information (Figure S3B), but the different two-sample methods indicated pleiotropy in different directions. The MR-Egger estimates suggested that the true association between BMI and specialist costs was higher than the IVW estimate. The median- and modal-based estimates, however, indicated that the true effect was smaller than the IVW estimate. The modal plot exhibited some evidence of modal pleiotropy (Figure S6B). Visual inspection of the funnel plot (Additional information, Figure S2B) indicated slight asymmetry indicating that the true value could be smaller than the IVW estimate. None of the two-sample estimates for specialist costs were statistically significant, but we had limited power to detect an effect. Since total costs were largely driven by specialist costs, the results for total costs were similar to those reported for specialist costs.

\subsubsection{Non-linear analyses}

There was some evidence of nonlinearity in the association between BMI and GP-costs (Additional information, Figure S7). The p-values from the quadratic and fractional polynomial tests were both $<0.05$. The corresponding tests for the association between BMI and specialist costs did not suggest nonlinearity. 


\subsubsection{Sex, healthcare provider, and age specific analyses}

In the 2SLS analyses, we found some indications that healthcare costs differed between males and females (Additional information, Table S3). For both males and females, we found an association between BMI and GP costs when using the unweighted and weighted GRSs ( $p$-value $<0.0001$ for males and females), but not when using the FTO \& MC4R instrument ( $p$-value $=0.386$ for males, $p$-value $=0.075$ for females). For both males and females, the second-stage coefficients when using the GRSs as instruments were similar to the OLS estimates, and the coefficients were smaller when using the FTO \& MC4R instrument.

For both males and females, we found no evidence of an association between BMI and specialist costs when using the three different instruments. Compared with the OLS estimates, the 2SLS coefficients were larger for males, and smaller (and negative) for females. However, we likely had insufficient power to detect effects of this size. Again, the results for total costs were similar to the results for specialist costs.

Stratifying specialist costs based on the healthcare provider indicated that the effects observed for specialist costs were mainly driven by costs incurred by patients that had received somatic care in hospitals (Additional information, Table S4). As with specialist costs overall, we found no significant association between $\mathrm{BMI}$ and healthcare costs, for any of the different healthcare providers. For costs incurred in somatic hospitals and for contacts with specialists on contract with specialist care providers, we found a negative effect (not significant) of BMI on costs for females, and a positive effect (significant only for somatic hospital costs when using the weighted GRS instrument) of BMI on costs for males.

\subsubsection{Outlier removal}

For GP costs, we found three (rs4740619, rs13191362, and rs4787491) right-lying outliers (Figure S4). One of these (rs4787491) had been found to be associated with several potentially confounding phenotypes (such as: age at menarche, time spent driving, employment status, and alcohol intake frequency). Removing one or all of the outliers from the analyses on GP costs (Additional information, Table S5) reduced the effect estimate by up to $14 \%$ when using the unweighted GRS, and by up to $11 \%$ when using the weighted GRS.

For specialist costs, we identified one (rs7715256) right-lying outlier (Figure S5). This variant had been found to be associated with age at menarche, and basal metabolic rate, in addition to BMI-related phenotypes. Removing this outlier from specialist costs resulted in lower effect estimates (Additional Information, Table S6), but the effects remained non-significant.

\subsubsection{Within-family analyses}

For GP costs, the results of the within-family analyses were similar to results from the full population analyses ( $€ 3.9$ smaller when using the unweighted and weighted GRSs, and $€ 1.0$ smaller when using the 
FTO \& MC4R instrument) (Additional information, Table S7). For specialist costs the within-family estimates were considerably smaller and negative when using all the instruments $(€ 67.9$ smaller when using the unweighted GRS, $€ 98.6$ smaller when using the weighted GRS, and $€ 155.6$ smaller when using the FTO and MC4R instrument), compared with the estimates from the full sample. None of the effect estimates were significant. However, since the sample was reduced to 29199 observations, and 11723 groups, we might have had insufficient power.

\section{Discussion}

Compared with the naïve OLS estimates we found small and precise estimates of the effect of BMI on GP costs. Our results indicate that a one-unit increase in BMI increases GP costs by less than $€ 5.6$ per year. Assuming linearity and that the difference in BMI between normal weight and obesity is $10.75 \mathrm{~kg} / \mathrm{m}^{2}$ these results suggest that obesity leads to a maximum of $€ 60.2$ higher GP-cost per year. For specialist costs, the main analyses suggested that the effect of BMI on specialist costs were smaller and less precise than the OLS estimate.

Previous studies assessing the effect of BMI on healthcare costs or utilization have found substantially higher costs and/or utilization when using the BMI of a relative [22-26] or when using genetic variants [27, 28] as instruments in IV-analyses, compared with the costs found using traditional methods. There are several potential explanations for why our results do not follow the same pattern. The studies that have used biological relatives as instruments are not able to rule out environmental effects to the same extent as studies using individuals' genetic variants as instruments. However, the use of biological relatives as instruments is also more powerful, as it may explain more of the variance in BMI compared with the use of genetic variants [67]. Nevertheless, this approach is limited because it omits individuals without children.

The two existing studies that have used genetic variants as instruments to assess the effect of $\mathrm{BMI}$ on healthcare costs both concluded that increased BMI leads to higher healthcare costs. One possible reason why our results do not follow the same trend is that there are differences between the data sources used. Compared with the first study, which was based on UK Biobank data [27], our sample had a larger response rate ( $54.1 \%$ in our data vs. $5.45 \%$ in the UK-based study), and included a broader age span (ages 20 and above in our data vs. $99.5 \%$ of the sample being between $40-69$ years of age in the UK-based study). The UK Biobank sample $(n=307$ 048) was larger than our sample $(n=60728)$. The second study by [28], conducted in South West Germany, had a small sample size for the MR context $(n=2796)$, and the data on healthcare utilization used to estimate costs were self-reported in interviews. Self-reported healthcare utilization could lead to bias, especially if the number of encounters are high [20]. Although the results of our study are not directly comparable with the studies by CF Kurz and M Laxy [28], and P Dixon, W Hollingworth, S Harrison, NM Davies and GD Smith [27], there were some noteworthy discrepancies between our findings. In our study and in the study by P Dixon, W Hollingworth, S Harrison, NM Davies and GD Smith [27] the findings suggested that BMI had a smaller effect on hospital costs for females than for males. While the findings from the study by CF Kurz and M Laxy [28] suggests that BMI 
may increase healthcare costs more among females. In our study, and in the study by P Dixon, W Hollingworth, S Harrison, NM Davies and GD Smith [27], the weighted median and modal estimates were smaller than the IVW estimates, while the weighted median estimate was higher than the IVW estimate in the study by CF Kurz and M Laxy [28]. Lastly, the MR-Egger estimate was smaller than the IVW estimate in the study by P Dixon, W Hollingworth, S Harrison, NM Davies and GD Smith [27] and in the study by CF Kurz and M Laxy [28], while in our study the MR Egger estimate was higher than the IVW estimate. These discrepancies are potentially relevant for evaluating the reliability of MR-based estimates.

There are also some important limitations of studies using genetic variants as instruments. First, our understanding of $\mathrm{BMI}$ is limited, and $\mathrm{BMI}$ is trait heterogeneous (i.e. the genetic pathways leading to high $\mathrm{BMI}$ are heterogeneous). For instance, some people may have genetic variants that lead to an increased probability of poor diet, others may be predisposed to low metabolism or overeating. Ideally, we should seek to identify genetic variants that are associated with different underlying causes, and assess the individual impact of each of these on BMI and healthcare costs. Second, our power calculations show that we may have had insufficient power to detect small effect sizes, and this may explain why we did not find a significant effect of BMI on specialist costs (Figure S1). This is an important problem, but at the same time, if obesity is associated with small costs, then the consequences of a type II error are smaller. Third, because our costs were calculated based on the average costs for a particular type of contact, we have not accounted for differences in costs between BMI-categories for the same type of contact. Fourth, although we have done our best to test the validity IV-assumptions, we need an improved understanding of how each of the genetic variants work to fully understand the limitations of their use [68]. Fifth, it is possible that the health consequences of acquiring obesity due to a genetic predisposition, differ from the health consequences of obesity acquired through environmental factors (e.g. social transmission). Lastly, since obesity is associated with early mortality [69], we may have captured a larger proportion of lifetime healthcare costs for persons with obesity, compared with those without. In addition to these limitations, our study lacked a sufficient sample size to conduct a wider range of sensitivity analyses.

If our results are correct then there is a causal effect of increased BMI on GP costs, but not necessarily on specialist costs, and the economic consequences of obesity on healthcare systems has been overestimated in previous studies. We also found that the BMI-related genetic variants that resulted in higher GP costs (Additional information, Figure S4) were not the same as the ones driving specialist costs (Additional information, Figure S5). Moreover, we found that different genetic variants were drivers of healthcare costs for males and females, and for different types of specialist care. Lastly, when using the GRSs the results were sometimes different compared with when we used the variants with the strongest association with BMI (FTO and MC4R). These findings might suggest that there are differences in the supply and/or demand of healthcare services for individuals with different genetic variants or groups of genetic variants. This could be related to the many different potential pathways leading to obesity, and increased knowledge on this topic could be relevant for evaluations of prevention and treatment strategies. 
The differing results found for males and females may also be explained by biological differences. National data on the number of sex-specific healthcare contacts made suggests that contact frequency is often higher for females than for males for diagnoses that are typically related to BMI (such as heart disease, diabetes, and circulatory diseases) (Additional information, Figure S8).

Since our study and all similar studies have different sample-related limitations, it will be important to conduct more studies, ideally with nationally representative data with a large sample size, and a broad age-span on participants. Future studies should also include as many newly discovered BMI-related genetic variants as possible. Finally, it could also be interesting to further investigate differences between the OLS and 2SLS estimates to try to uncover potential sources of simultaneity bias, for instance by comparing effect estimates for specific types of healthcare contact.

\section{Conclusion}

The effect of BMI on healthcare cost attenuated in the IV models, compared with the naïve OLS models. Previous studies may have overestimated the effects of obesity on GP and specialist costs.

\section{Abbreviations}

BMl: Body Mass Index

HUNT: Nord-Trøndelag Health Studies

GP: General Practitioner

IV: Instrumental Variable

OLS: Ordinary Least Squares

MR: Mendelian randomization

NPR: Norwegian Patient Registry

KUHR: Norwegian Control and Payment of Health Reimbursement

DRG: Diagnosis Related Group

NOK: Norwegian Kroner

NUDB: National Education Database

2SLS: Two-Stage Least Squares

GWAS: Genome Wide Association Study 


\section{Declarations}

\section{Ethics approval and consent to participate}

The study was approved and participant consent was waived (because the data used in the study were registry-based) by the Regional Committee for Medical and Health Research Ethics Central Norway (2016/537/REK midt).

\section{Consent for publication}

Not applicable.

\section{Availability of data and material}

The data that support the findings of this study are available from third parties. Restrictions apply to the availability of these data, which were used under license for this study. Please contact the corresponding author for more information about data accessibility.

\section{Competing interests}

The authors declare that they have no competing interests.

\section{Funding}

This research project was funded by the Norwegian Research Council; Grant number: 250335/F20. The funding body had no role in study design, in collection, interpretation or analysis of the data, in writing the manuscript, or in the decision to submit the manuscript for publication.

\section{Authors' contributions}

$\mathrm{CHE}, \mathrm{JMK}$, and GÅV contributed to the design of the study. Data analyses were done by CHE, and interpretation of study findings was done by CME, JMK and GÅV. The manuscript was written by $\mathrm{CHE}$, JMK, and GÅV. All authors have seen and approved the final version of the manuscript.

\section{Acknowledgements}

The Nord-Trøndelag Health Study (The HUNT Study) is a collaboration between HUNT Research Centre, (Faculty of Medicine and Health Sciences, NTNU, Norwegian University of Science and Technology), Trøndelag County Council, Central Norway Regional Health Authority, and the Norwegian Institute of Public Health.

\section{References}

1. Ng M, Fleming T, Robinson M, Thomson B, Graetz N, Margono C, Mullany EC, Biryukov S, Abbafati C, Abera SF: Global, regional, and national prevalence of overweight and obesity in children and adults 
during 1980-2013: a systematic analysis for the Global Burden of Disease Study 2013. The Lancet 2014, 384(9945):766-781. doi: 10.1016/S0140-6736(14)60460-8

2. Wang Y, Cai L, Wu Y, Wilson RF, Weston C, Fawole O, Bleich SN, Cheskin LJ, Showell NN, Lau BD et al: What childhood obesity prevention programmes work? A systematic review and meta-analysis. Obesity Reviews : an official journal of the International Association for the Study of Obesity 2015, 16(7):547-565. doi: 10.1111/obr.12277

3. Khera R, Murad MH, Chandar AK, Dulai PS, Wang Z, Prokop LJ, Loomba R, Camilleri M, Singh S: Association of pharmacological treatments for obesity with weight loss and adverse events: a systematic review and meta-analysis. JAMA 2016, 315(22):2424-2434. doi:

10.1001/jama.2016.7602

4. Teixeira PJ, Carraça EV, Marques MM, Rutter H, Oppert J-M, De Bourdeaudhuij I, Lakerveld J, Brug J: Successful behavior change in obesity interventions in adults: a systematic review of self-regulation mediators. BMC medicine 2015, 13(1):84. doi: 10.1186/s12916-015-0323-6

5. Douketis J, Macie C, Thabane L, Williamson D: Systematic review of long-term weight loss studies in obese adults: clinical significance and applicability to clinical practice. International Journal of Obesity 2005, 29(10):1153. . doi: 10.1038/sj.ijo.0802982

6. Tran BX, Nair AV, Kuhle S, Ohinmaa A, Veugelers PJ: Cost analyses of obesity in Canada: scope, quality, and implications. Cost Effectiveness and Resource Allocation 2013, 11(1):3. doi:

10.1186/1478-7547-11-3

7. Thompson D, Wolf AM: The medical-care cost burden of obesity. Obesity Reviews 2001, 2(3):189197. doi: 10.1046/j.1467-789x.2001.00037.x

8. Müller-Riemenschneider F, Reinhold T, Berghöfer A, Willich SN: Health-economic burden of obesity in Europe. European Journal of Epidemiology 2008, 23(8):499-509. doi: 10.1007/s10654-008-9239-1

9. Tremmel M, Gerdtham U-G, Nilsson P, Saha S: Economic burden of obesity: a systematic literature review. International Journal of Environmental Research and Public Health 2017, 14(4):435. doi: 10.3390/ijerph14040435

10. Kortt MA, Langley PC, Cox ER: A review of cost-of-illness studies on obesity. Clinical Therapeutics 1998, 20(4):772-779. doi: 10.1016/s0149-2918(98)80140-9

11. Kim DD, Basu A: Estimating the medical care costs of obesity in the United States: systematic review, meta-analysis, and empirical analysis. Value in Health 2016, 19(5):602-613. doi:

10.1016/j.jval.2016.02.008

12. von Lengerke T, Krauth C: Economic costs of adult obesity: a review of recent European studies with a focus on subgroup-specific costs. Maturitas 2011, 69(3):220-229. doi:

10.1016/j.maturitas.2011.04.005

13. Hammond RA, Levine R: The economic impact of obesity in the United States. Diabetes Metab Syndr Obes 2010, 3(1):285-295. doi: 10.2147/DMSOTT.S7384

14. Kent S, Fusco F, Gray A, Jebb SA, Cairns BJ, Mihaylova B: Body mass index and healthcare costs: a systematic literature review of individual participant data studies. Obesity Reviews 2017, 18(8):869- 
879. doi: $10.1111 /$ obr. 12560

15. Tsai AG, Williamson DF, Glick HA: Direct medical cost of overweight and obesity in the USA: a quantitative systematic review. Obesity Reviews 2011, 12(1):50-61. doi: 10.1111/j.1467789X.2009.00708.x

16. Withrow D, Alter D: The economic burden of obesity worldwide: a systematic review of the direct costs of obesity. Obesity Reviews 2011, 12(2):131-141. doi: 10.1111/j.1467-789X.2009.00712.x

17. Leslie WS, Hankey CR, Lean MEJ: Weight gain as an adverse effect of some commonly prescribed drugs: a systematic review. QJM: An International Journal of Medicine 2007, 100(7):395-404. doi: 10.1093/qjmed/hcm044

18. Krul AJ, Daanen HA, Choi H: Self-reported and measured weight, height and body mass index (BMI) in Italy, the Netherlands and North America. The European Journal of Public Health 2011, 21(4):414419. doi: 10.1093/eurpub/ckp228

19. Kuczmarski MF, Kuczmarski RJ, Najjar M: Effects of Age on Validity of Self-Reported Height, Weight, and Body Mass Index: Findings from the Third National Health and Nutrition Examination Survey, 1988-1994. Journal of the American Dietetic Association 2001, 101(1):28-34. doi: 10.1016/S00028223(01)00008-6

20. Ritter PL, Stewart AL, Kaymaz H, Sobel DS, Block DA, Lorig KR: Self-reports of health care utilization compared to provider records. Journal of Clinical Epidemiology 2001, 54(2):136-141. Doi: 10.1016/S0895-4356(00)00261-4

21. O'Neill D, Sweetman O: The consequences of measurement error when estimating the impact of obesity on income. IZA Journal of Labor Economics 2013, 2(1):3. doi: 10.1186/2193-8997-2-3

22. Biener Al, Cawley J, Meyerhoefer C: The medical care costs of youth obesity: An instrumental variables approach. In.: National Bureau of Economic Research; 2017. doi: 10.1002/hec.4007

23. Black N, Hughes R, Jones AM: The health care costs of childhood obesity in Australia: An instrumental variables approach. Economics \& Human Biology 2018, 31:1-13. doi:

10.1016/j.ehb.2018.07.003

24. Kinge JM, Morris S: The impact of childhood obesity on health and health service use. Health Services Research 2018, 53(3):1621-1643. doi: 10.1111/1475-6773.12708

25. Cawley J, Meyerhoefer C: The medical care costs of obesity: an instrumental variables approach. Journal of Health Economics 2012, 31(1):219-230. doi: 10.1016/j.jhealeco.2011.10.003

26. Doherty E, Queally M, Cullinan J, Gillespie P: The impact of childhood overweight and obesity on healthcare utilisation. Economics \& Human Biology 2017, 27(Pt A):84-92. doi:

10.1016/j.ehb.2017.05.002

27. Dixon P, Hollingworth W, Harrison S, Davies NM, Smith GD: Mendelian Randomization analysis of the causal effect of adiposity on hospital costs. Journal of Health Economics 2020, 70:102300. doi: 10.1016/j.jhealeco.2020.102300

28. Kurz CF, Laxy M: Application of Mendelian Randomization to Investigate the Association of Body Mass Index with Health Care Costs. Medical Decision Making 2020, 40(2):156-169. . doi: 
$10.1177 / 0272989 \times 20905809$

29. Locke AE, Kahali B, Berndt SI, Justice AE, Pers TH, Day FR, Powell C, Vedantam S, Buchkovich ML, Yang J: Genetic studies of body mass index yield new insights for obesity biology. Nature 2015, 518(7538):197-206. doi: 10.1038/nature14177

30. Krokstad S, Langhammer A, Hveem K, Holmen TL, Midthjell K, Stene TR, Bratberg G, Heggland J, Holmen J: Cohort profile: The HUNT study, Norway. Int J Epidemiol 2013, 42(4):968-977. doi:

10.1093/ije/dys095

31. Holmen J, Midthjell K, Krüger $\varnothing$, Langhammer A, Holmen TL, Bratberg GH, Vatten L, Lund-Larsen PG: The Nord-Trøndelag Health Study 1995-97 (HUNT 2): Objectives, contents, methods and participation. Norsk Epidemiologi 2003, 13(1):19-32.

32. Styringsdata for fastlegeordningen 4. kvartal 2018. [https://www.helsedirektoratet.no/statistikk/statistikk/fastlegestatistikk\#fastlegestatistikk-2018]

33. Bakken IJ, Ariansen AM, Knudsen GP, Johansen KI, Vollset SE: The Norwegian Patient Registry and the Norwegian Registry for Primary Health Care: Research potential of two nationwide health-care registries. Scandinavian Journal of Public Health 2019, 48(1). doi: 10.1177/1403494819859737

34. Innsatsstyrt Finansiering 2009 [https://www.helsedirektoratet.no/tema/finansiering/innsatsstyrtfinansiering-og-drg-systemet/innsatsstyrt-finansiering-isf]

35. Innsatsstyrt Finansiering 2010 [https://www.helsedirektoratet.no/tema/finansiering/innsatsstyrtfinansiering-og-drg-systemet/innsatsstyrt-finansiering-isf]

36. Innsatsstyrt Finansiering 2011 [https://www.helsedirektoratet.no/tema/finansiering/innsatsstyrtfinansiering-og-drg-systemet/innsatsstyrt-finansiering-isf]

37. Innsatsstyrt Finansiering 2012 [https://www.helsedirektoratet.no/tema/finansiering/innsatsstyrtfinansiering-og-drg-systemet/innsatsstyrt-finansiering-isf]

38. Innsatsstyrt Finansiering 2013 [https://www.helsedirektoratet.no/tema/finansiering/innsatsstyrtfinansiering-og-drg-systemet/innsatsstyrt-finansiering-isf]

39. Innsatsstyrt Finansiering 2014 [https://www.helsedirektoratet.no/tema/finansiering/innsatsstyrtfinansiering-og-drg-systemet/innsatsstyrt-finansiering-isf]

40. Innsatsstyrt Finansiering 2015 [https://www.helsedirektoratet.no/tema/finansiering/innsatsstyrtfinansiering-og-drg-systemet/innsatsstyrt-finansiering-isf]

41. Innsatsstyrt Finansiering 2016 [https://www.helsedirektoratet.no/tema/finansiering/innsatsstyrtfinansiering-og-drg-systemet/innsatsstyrt-finansiering-isf]

42. Makroøkonomiske hovedstørrelser 2003-2017. Regnskap og prognoser. Prosentvis endring fra året før der ikke annet framgår. [https://www.ssb.no/209660/makroøkonomiske-hovedstørrelser-20032017.regnskap-og-prognoser.prosentvis-endring-fra-året-før-der-ikke-annet-framgår]

43. Makroøkonomiske hovedstørrelser 2009-2022. Regnskap og prognoser. Prosentvis endring fra året før der ikke annet framgår.

44. Valutakurser [https://www.norges-bank.no/tema/Statistikk/valutakurser/] 
45. Boyle EA, Li YI, Pritchard JK: An expanded view of complex traits: from polygenic to omnigenic. Cell 2017, 169(7):1177-1186. doi: 10.1016/j.cell.2017.05.038

46. Brion M-JA, Shakhbazov K, Visscher PM: Calculating statistical power in Mendelian randomization studies. International Journal of Epidemiology 2013, 42(5):1497-1501. doi: 10.1093/ije/dyt179

47. Brandkvist M, Bjørngaard JH, Ødegård RA, Åsvold BO, Sund ER, Vie GÅ: Quantifying the impact of genes on body mass index during the obesity epidemic: longitudinal findings from the HUNT Study. BMJ 2019, 366:I4067. doi: 10.1136/bmj.14067

48. Yengo L, Sidorenko J, Kemper KE, Zheng Z, Wood AR, Weedon MN, Frayling TM, Hirschhorn J, Yang $\mathrm{J}$, Visscher PM et al: Meta-analysis of genome-wide association studies for height and body mass index in $~ 700000$ individuals of European ancestry. Human Molecular Genetics 2018, 27(20):36413649. doi: $10.1093 / \mathrm{hmg} /$ ddy 271

49. Staiger DO, Stock JH: Instrumental variables regression with weak instruments. In.: National Bureau of Economic Research Cambridge, Mass., USA; 1994.

50. Burgess S, Thompson SG: Bias in causal estimates from Mendelian randomization studies with weak instruments. Statistics in Medicine 2011, 30(11):1312-1323. doi: 10.1002/sim.4197

51. Palmer TM, Lawlor DA, Harbord RM, Sheehan NA, Tobias JH, Timpson NJ, Smith GD, Sterne JA: Using multiple genetic variants as instrumental variables for modifiable risk factors. Statistical Methods in Medical Research 2012, 21(3):223-242. doi: 10.1177/0962280210394459

52. Price AL, Patterson NJ, Plenge RM, Weinblatt ME, Shadick NA, Reich D: Principal components analysis corrects for stratification in genome-wide association studies. Nature genetics 2006, 38(8):904. doi: $10.1038 / \mathrm{ng} 1847$

53. Hemani G, Bowden J, Davey Smith G: Evaluating the potential role of pleiotropy in Mendelian randomization studies. Hum Mol Genet 2018, 27(R2):R195-r208. doi: 10.1093/hmg/ddy163

54. Bowden J, Davey Smith G, Burgess S: Mendelian randomization with invalid instruments: effect estimation and bias detection through Egger regression. International Journal of Epidemiology 2015, 44(2):512-525. doi: 10.1093/ije/dyv080

55. Bowden J, Del Greco M F, Minelli C, Davey Smith G, Sheehan NA, Thompson JR: Assessing the suitability of summary data for two-sample Mendelian randomization analyses using MR-Egger regression: the role of the 12 statistic. International Journal of Epidemiology 2016, 45(6):1961-1974. doi: $10.1093 /$ ije/dyw220

56. Zheng J, Baird D, Borges M-C, Bowden J, Hemani G, Haycock P, Evans DM, Smith GD: Recent developments in Mendelian randomization studies. Current Epidemiology Reports 2017, 4(4):330345. doi: 10.1007/s40471-017-0128-6

57. Bowden J, Davey Smith G, Haycock PC, Burgess S: Consistent Estimation in Mendelian Randomization with Some Invalid Instruments Using a Weighted Median Estimator. Genetic Epidemiology 2016, 40(4):304-314. doi: 10.1002/gepi.21965

58. Bowden J, Holmes MV: Meta-analysis and Mendelian randomization: A review. Research Synthesis Methods 2019, 10(4):486-496. doi: 10.1002/jrsm.1346 
59. Hartwig FP, Davey Smith G, Bowden J: Robust inference in summary data Mendelian randomization via the zero modal pleiotropy assumption. International Journal of Epidemiology 2017, 46(6):19851998. doi: $10.1093 / \mathrm{ije} /$ dyx102

60. Budu-Aggrey A, Brumpton B, Tyrrell J, Watkins S, Modalsli EH, Celis-Morales C, Ferguson LD, Vie GÅ, Palmer T, Fritsche LG: Evidence of a common causal relationship between body mass index and inflammatory skin disease: a Mendelian Randomization study. BioRxiv 2018:265629.

61. Laxy M, Stark R, Peters A, Hauner H, Holle R, Teuner CM: The non-linear relationship between bmi and health care costs and the resulting cost fraction attributable to obesity. International Journal of Environmental Research and Public Health 2017, 14(9):984. doi: 10.3390/ijerph14090984

62. Sun Y-Q, Burgess S, Staley JR, Wood AM, Bell S, Kaptoge SK, Guo Q, Bolton TR, Mason AM, Butterworth AS et al: Body mass index and all cause mortality in HUNT and UK Biobank studies: linear and non-linear mendelian randomisation analyses. BMJ 2019, 364:11042. doi: $10.1136 / \mathrm{bmj} .11042$

63. Staley JR, Burgess S: Semiparametric methods for estimation of a nonlinear exposure-outcome relationship using instrumental variables with application to Mendelian randomization. Genetic epidemiology 2017, 41(4):341-352. doi: 10.1002/gepi.22041

64. Brumpton B, Sanderson E, Hartwig FP, Harrison S, Vie GA, Cho Y, Howe L, Hughes A, Boomsma D, Havdahl A: Within-family studies for Mendelian randomization: avoiding dynastic, assortative mating, and population stratification biases. bioRxiv 2019:602516.

65. Staley JR, Blackshaw J, Kamat MA, Ellis S, Surendran P, Sun BB, Paul DS, Freitag D, Burgess S, Danesh J et al: PhenoScanner: a database of human genotype-phenotype associations. Bioinformatics 2016, 32(20):3207-3209. doi: 10.1093/bioinformatics/btw373

66. Spiller W, Davies NM, Palmer TM: Software application profile: mrrobust-a tool for performing twosample summary Mendelian randomization analyses. International Journal of Epidemiology 2018, 48(3):684-690. doi: 10.1093/ije/dyy195

67. Cawley J: An economy of scales: A selective review of obesity's economic causes, consequences, and solutions. Journal of Health Economics 2015, 43:244-268. doi: 10.1016/j.jhealeco.2015.03.001

68. Cawley J, Han E, Norton EC: The validity of genes related to neurotransmitters as instrumental variables. Health Economics 2011, 20(8):884-888. doi: 10.1002/hec.1744

69. Aune D, Sen A, Prasad M, Norat T, Janszky I, Tonstad S, Romundstad P, Vatten LJ: BMI and all cause mortality: systematic review and non-linear dose-response meta-analysis of 230 cohort studies with 3.74 million deaths among $\mathbf{3 0 . 3}$ million participants. BMJ 2016, 353:i2156. doi: 10.1136/bmj.i2156

\section{Figures}




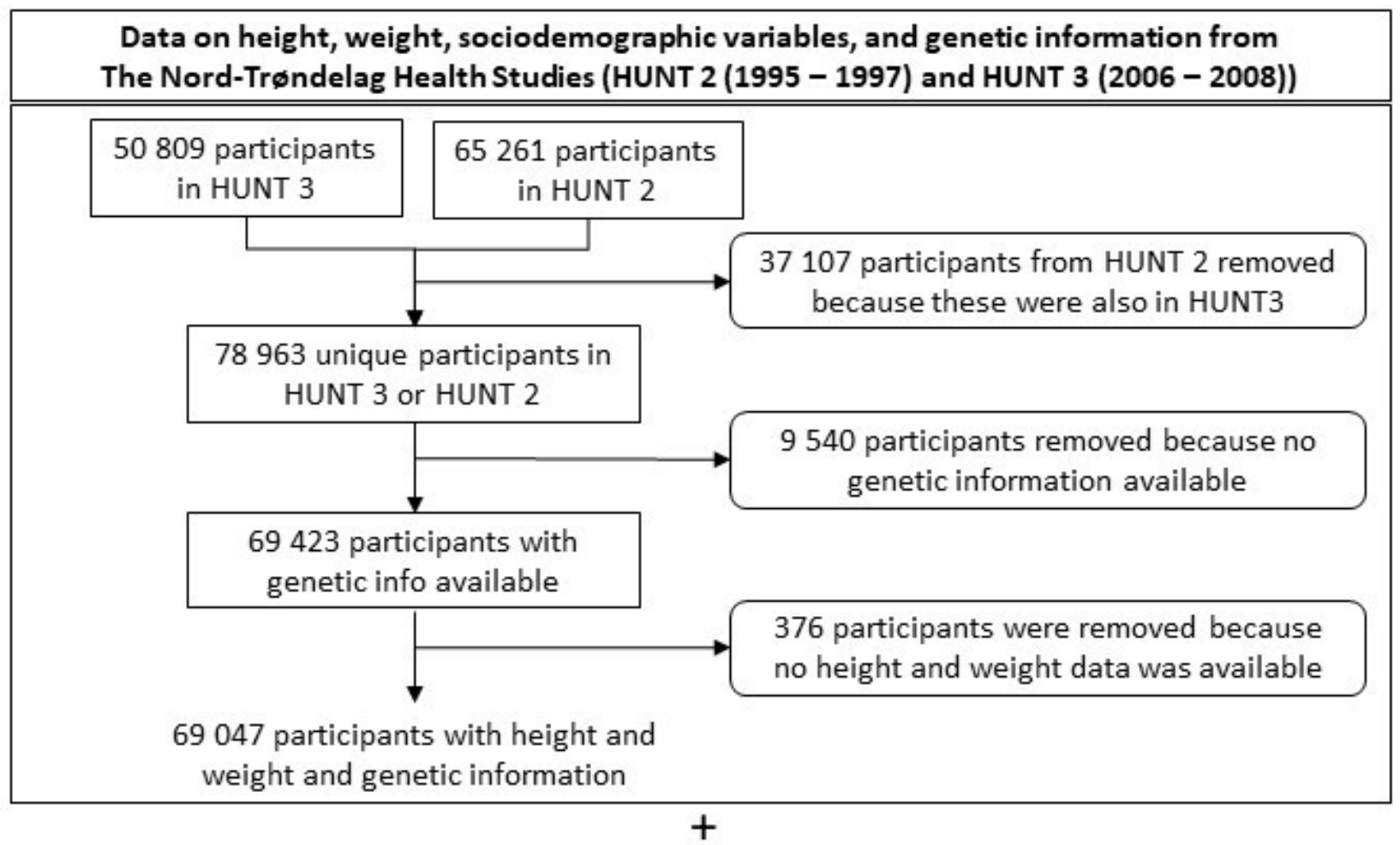

Data on secondary care costs between 2009 and 2016 from the Norwegian Patient Register (NPR)

42407 participants were registered in the NPR database, those not included ( $n=26640)$ were assumed not to have had utilized secondary care services between 2009 and 2016.

$$
+
$$

Data on GP-reimbursements between 2009 and 2016 from The Norwegian Control and Distribution of Health Reimbursement Database (KUHR).

61064 participants were registered in the KUHR database, those not included $(n=7983)$ were assumed not to have had contact with primary care between 2009 and 2016.

$$
+
$$

Data on education from the National Education Database (NUDB) from 2009 - 2016

All 69047 participants were registered in the NUDB database, but information about education at the same time as BMI was measured was missing for 225 participants.

$$
+
$$

Data on registration status from 2009 - 2016 and relatedness from the Norwegian Population Register

60786 of the participants were registered as alive and living in Norway one or more years between 2009 and 2016, and 8261 had either died or emigrated or had missing information for all years between 2009 and 2016. In total 29199 participants had the same mother and father.

\section{Figure 1}

Overview of data sources used in the study. 

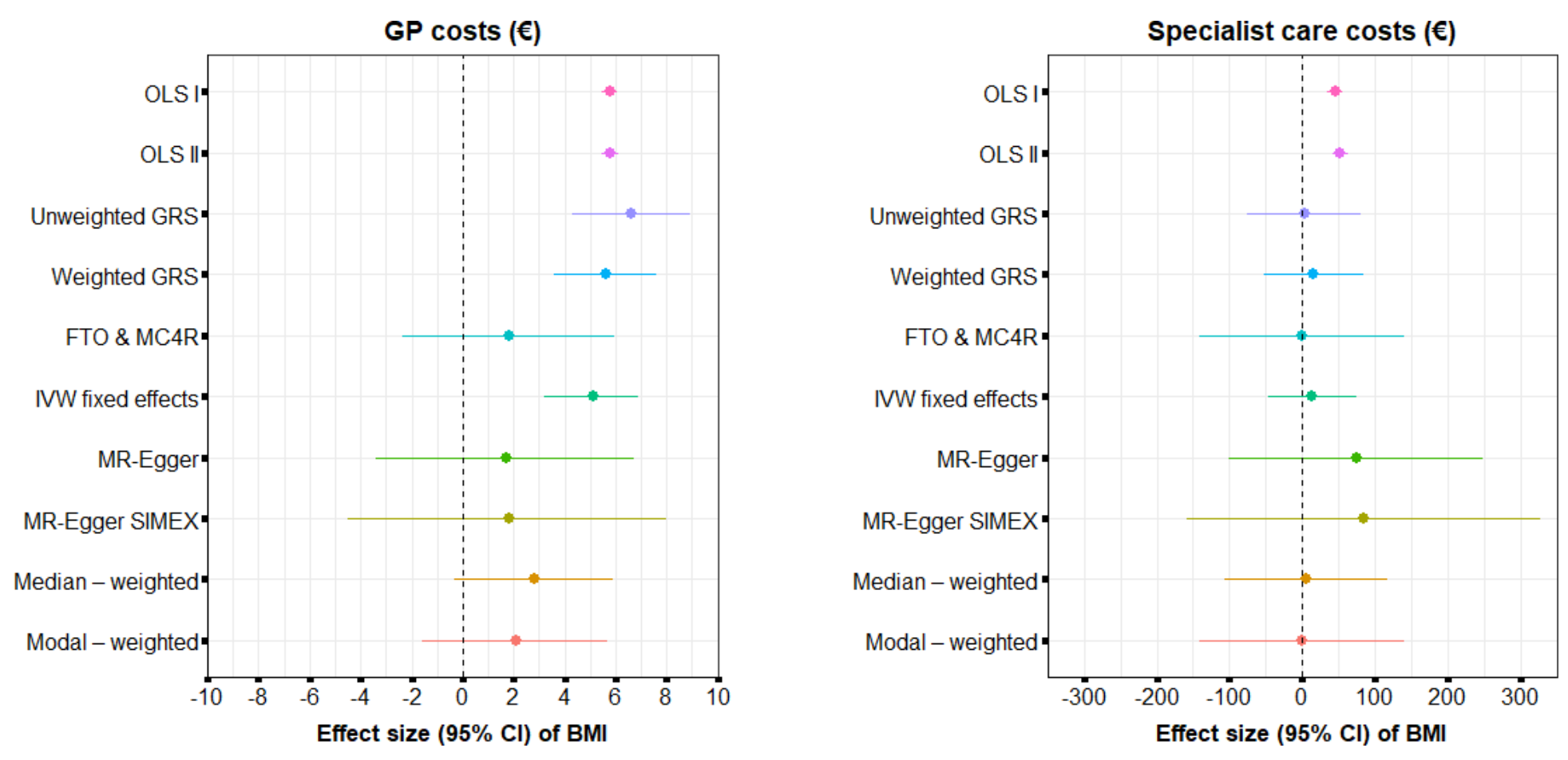

Figure 2

Estimates and 95\% confidence intervals (Cls) of the effect of BMI on GP (left) and specialist (right) costs using OLS, one-sample, and two-sample methods.

\section{Supplementary Files}

This is a list of supplementary files associated with this preprint. Click to download.

- Additionallnformation.docx 